\title{
Diyabet Hastalarında D Vitamini ile Hba1c İlişkisinin Değerlendirilmesi
}

\section{Evaluation of the Relationship Between Vitamin $D$ and Hba1c Levels in Diabetic Patients}

Duygu İlke Yıldırım",

Kamile Marakoğlu²

'Sağlık Bilimleri Üniversitesi, Konya Eğitim ve Araştırma Hastanesi, Aile Hekimliği Kliniği, Konya, Türkiye

${ }^{2}$ Selçuk Üniversitesi Tıp Fakültesi Aile Hekimliği AD, Konya, Türkiye

Gelis Tarihi/Received: 6 Ocak 2018

Kabul Tarihi/Accepted: 13 Temmuz 2018

Yazışma Adresi: Duygu İlke Yıldırım, Sağlık Bilimleri Üniversitesi, Konya Eğitim ve Araştırma Hastanesi, Aile Hekimliği Kliniği, Konya, Türkiye

e-posta: azrailla@hotmail.com

ORCID

Duygu İlke Yıldırım

https://orcid.org/0000-0002-3893-5173

\section{GíRiş}

Diabetes mellitus (DM), tüm dünyada çok fazla görülen insülin üretiminin azalması nedeniyle (Tip 1 DM) ya da insülin etkisine karşı direnç geliş̧mesi sebebiyle (Tip 2 DM) oluşan organizmanın

Atıf yapmak için: Yıldırım Dí, Marakoğlu K. Diyabet Hastalarında D Vitamini ile Hba1c İlişkisinin Değerlendirilmesi. Selcuk Med J 2019;35(1): $37-42$

\begin{abstract}
Öz
Amaç: Diyabet son yıllarda hızla artış gösteren, ciddi komplikasyonlara yol açan bir sağlık problemidir. D vitamini düzeyi diyabetin kontrolüne katkıda bulunan bir faktör olarak belirtilmektedir. Bu çalışmada diyabetik hastalarda $D$ vitamin düzeylerini ve glisemik kontrol arasındaki ilişkiyi değerlendirmek amaçlanmıştır.

Hastalar ve Yöntem: Çalışmaya Diyabet Eğitim Polikliniği'ne Eylül 2015 - Haziran 2016 tarihleri arasında başvuran takip ve tedavi altındaki 330 diyabetik hasta alındı. Çalışmaya 18 yaş ve üzerinde olan hastalar dahil edildi. Hastalar vitamin D düzeylerine göre; $\leq 20 \mathrm{ng} / \mathrm{mL}, 20-30 \mathrm{ng} / \mathrm{mL}$ arasında ve $\geq 30 \mathrm{ng} / \mathrm{mL}$ olmak üzere üç gruba ayrılarak kategorize edildi. Bu gruplar hastaların sosyo-demografik özellikleri, kan parametreleri, diyabet ile ilgili özellikleri ve diyabet tedavileri yönünden karşılaştırıldı. HbA1c düzeylerine göre $\leq \% 7$ altı ve $>\% 7$ üzeri olmak üzere iki gruba kategorize edildi. Bu iki grupta da aynı parametreler ve D vitamini değerleri karşılaştırıldı.

Bulgular: Çalışmaya alınan 330 diyabetik hastanın \%51,2'si $(n=169)$ kadın ve \%48,8'i ( $n=161)$ erkekti. Hastaların yaş ortalamaları 53,79 $\pm 10,2$ yıl idi. Çalışmamıza alınan hastalar VKI açısından değerlendirildiğinde \%13,9'u ( $n=46)$ normal 作 ayrıldığında, vitamin D seviyesi $20 \mathrm{ng} / \mathrm{mL}$ 'nin altında 286 hasta $(\% 86,7), 20 \mathrm{ng} / \mathrm{mL}$ 'nin üzerinde 44 hasta $(\% 13,3)$ saptandı. Hastalar D vitamini düzeylerine göre karşılaştırıldığında D vitamini değerleri ile hastaların açlık kan şekeri (AKŞ), tokluk kan sekeri (TKŞ) arasında negatif korelasyon $(-r=0,357, p<0,001,-r=0,344, p<0.001$ sırasıyla) bulundu. $D$ vitamini değerleri ile geğerleri arasında negatif korelasyon olduğu $(-r=0,433, p<0.001)$ tespit edildi. $D$ vitamini ile trigliserid düzeyi arasında negatif yönde korelasyon $(-r=0,131, p<0,05)$ saptandı.

(aç: Çalışmamızda D vitamini düzeylerine göre istatistiksel değerlendirme yapıldığında; HbA1c>\%7 olanların ( $n=191$ ), $\mathrm{HbA} 1 c<7$ olanlara $(n=95)$ göre $D$ vitamini düzeyleri istatistiksel olarak anlamlı derecede daha düşüktü $(p<0,001)$. Bu sonuçlar D vitamini seviyelerinin diyabet hastalarında glisemik kontrolde önemli olduğu kanısını desteklemektedir.
\end{abstract}

Anahtar Kelimeler: D vitamini, Tip 2 diyabetes mellitus, $\mathrm{HbA} 1 \mathrm{C}$

\begin{abstract}
Aim: Diabetes is a serious health problem which has increased rapidly in recent years and causes numerous complications. Vitamin D levels may be a contributing factor to the glycemic control. The aim of the study was to evaluate the relationship between vitamin $\mathrm{D}$ levels and glycemic control in diabetic patients.

Patients and Methods: 330 patients with Diabetes Mellitus type 2, who were admitted to our outpatient clinic between September 2015 and June 2016, were included in the study. Patients were stratified into three groups according to the vitamin D levels; $\leq 20 \mathrm{ng} / \mathrm{mL}$, between $20-30 \mathrm{ng} / \mathrm{mL}$ and $\geq 30 \mathrm{ng} / \mathrm{mL}$. These groups were compared in terms of patients' socio-demographic characteristics, blood parameters, diabetes-related characteristics, and diabetes treatment. Patients were categorized into two groups according to the $\mathrm{HbA} 1 \mathrm{c}$ levels; $\leq 7 \%$ and $\geq 7 \%$. The same parameters and vitamin $\mathrm{D}$ values were compared between two groups.

Results: A total of 330 patients $(51.2 \%$ females, mean age $53,79 \pm 10,2$ years) with diabetes were interviewed. When evaluated in terms of body mass index, $13.9 \%(n=46)$ were classified as normal, $34.5 \%(n=114)$ were overweight and $51.5 \%(n=170)$ were obese. When patients were divided into groups according to vitamin D levels, $286(86.7 \%)$ patients with a vitamin D level below $20 \mathrm{ng} / \mathrm{mL}$ and 44 patients $(13.3 \%)$ with a level above $20 \mathrm{ng} / \mathrm{mL}$ were detected. When patients were compared according to vitamin $D$ levels, there was a negative correlation $(-r=0.357, p<0.001,-r=0.344, p<0.001$, respectively) between vitamin $D$ levels and patients' fasting blood glucose level (FBG) and postprandial glucose level (PBG) There was a negative correlation $(-r=0.433, p<0.001)$ between vitamin $D$ levels and $\mathrm{HbA} 1 \mathrm{c}$ levels. Negative correlation $(-r$ $=0.131, p<0.05)$ was found between vitamin $D$ and triglyceride levels.

Conclusion: Vitamin D levels were significantly lower in patients with $\mathrm{HbA} 1 \mathrm{c}>7 \%(\mathrm{n}=191)$ when compared to those with $\mathrm{HbA1}<<(n=95)(p<0.001)$. Vitamin D levels may be important in glycemic control of diabetic patients.
\end{abstract}

Keywords: Vitamin D, Type 2 Diabetes Mellitus, HbA1c karbonhidrat, yağ ve proteinlerden yeteri kadar faydalanamadığı sonuçta devamlı tıbbi bakım gerektiren kronik bir metabolizma hastalığıdır. DM gelişmesinde fazla kilolu olma (obezite), birinci dereceden akrabalarda DM öyküsünün varlığı, insülin 
direnci ile alakalı bir klinik tablo varlığı, daha önce tanı almış glukoz intoleransı varlığı gibi risk faktörleri ile birlikte yanlış beslenme düzeni, virüsler, toksinler, emosyonel stres, sedanter hayat gibi çevresel ve genetik faktörlerin rol oynadığı bilinmektedir $(1,2)$. Son dönemde yapılan birçok çalışmada D vitamini eksikliğinin DM için bir risk faktörü olduğu ve bu eksikliğin glukoz tolerans bozukluğu ve insülin direnci ile ilişkili olduğu belirtilmektedir.

Sedanter yaşam tarzında ki artış ile birlikte dünya DM prevalansı hızla yükselmiş ve Dünya Sağlık Örgütü (DSÖ) tarafından bu durum epidemi olarak tanımlanmıştır. International Diabetes Federation (IDF) verilerine göre 2013'te dünya üzerindeki DM hasta sayısının 382 milyon olduğu ve 2035 yılında bu rakamın 592 milyona erişeceği öngörülmektedir. Türkiye de DM görülme sıklığındaki artışın en fazla olduğu ülkelerden biri olmuştur ve 1998 yılında \%7,22 olan DM prevalansı 12 yılda çok hızlı bir artışla \%13,7'ye yükselmiştir. Şimdiye kadar elde edilen en güçlü kanıt ise yetersiz D vitamini durumu ile Tip 1 DM veya Tip 2 DM vakaları arasında bir ilişki olduğunu gösteren gözlemsel çalışmalardan gelmektedir (3-7). DM patogenezinde $D$ vitamini eksikliğinin nedensel rolünü destekleyen kesin kanıtlar ve bu nedenle $D$ vitamini desteği için terapötik bir rol randomize klinik çalışmalardan gelmelidir. Günümüzde çok farklı hasta gruplarını içeren, farklı yapıda ve süreye sahip olan, birçok D vitamini çeşidinin kullanıldığı bazı çalışmalar yapılmıştır.

DM son yıllarda hızla artış gösteren, ciddi komplikasyonlara yol açan ciddi bir sağlık problemidir. D vitamini düzeyinin, diyabetin kontrolüne katkıda bulunan bir faktör olduğu belirtilmelidir. Bu çalışmanın amacı; DM'li hastalarda D vitamini düzeylerini ve glisemik kontrol arasındaki ilişkiyi değerlendirerek D vitaminini, glikoz metabolizması değişikliklerinin yönetiminde desteklemeye çalışmaktır.

\section{HASTALAR VE YÖNTEM}

Bu çalışmaya DM Eğitim Polikliniği'ne Eylül 2015 - Haziran 2016 tarihleri arasında başvuran Amerikan Diyabet Birliği'nin kılavuzunda (ADA 2017) belirtilen kriterlere göre teşhisi konulmuş erişkin tip 2 DM hastalığı olan, takip ve tedavi altında ki 330 DM'lu hasta alındı. Çalışmaya 18 yaş ve üzerinde olan ve Vit D düzeylerine bakılmış hastalar dahil edildi. Hastalar vitamin $D$ düzeylerine göre; $\leq 20 \mathrm{ng} / \mathrm{mL}, 20-30 \mathrm{ng} /$ $\mathrm{mL}$ arasında ve $\geq 30 \mathrm{ng} / \mathrm{mL}$ olmak üzere üç gruba ayrılarak kategorize edildi. Bu gruplar hastaların sosyo-demografik özellikleri, kan parametreleri,
DM ile ilgili özellikleri ve DM tedavileri yönünden karşılaştırıldı. HbA1c düzeylerine göre $\leq \% 7$ altı ve $>\% 7$ üzeri olmak üzere iki gruba kategorize edildi. Bu iki grupta da aynı parametreler ve $D$ vitamini değerleri karşılaştırıldı. Hastaların Vit $\mathrm{D} \geq 30 \mathrm{ng} / \mathrm{mL}$ ise; yeterli düzey, Vit $D=20-29 \mathrm{ng} / \mathrm{mL}$ arasında ise; yetersizlik, Vit $D<20 \mathrm{ng} / \mathrm{mL}$ ise bu durum Vit $D$ eksikliği olarak tanımlandı $(8,9)$.

\section{Istatistiksel Analiz}

Bu çalışmada elde edilen demografik özellikler, DM ile ilgili özellikler ve Vit D düzeyleri ile ilgili özellikler için istatistikler Frekans (n) ve Yüzde (\%) değerleri olarak verildi. Bununla birlikte Vit $D$ düzeylerinin kategorik değişkenlere göre karşılaştırılmasında Kikare testi (Chi square) kullanıldı. Verilerin normalliği Kolmogorov Smirnov normallik testi kullanılarak kontrol edildi. Korelasyon için pearson korelasyon analizi kullanıldı. İstatistiksel olarak anlamlı farklılık için $p<0,05$ değeri kullanılmış olup sonuçlar \%95'lik güven aralığında değerlendirildi. İstatistiksel analizler IBM SPSS (Statistical Package for Social Sciences) for Windows 21.0 paket programı yardımıyla gerçekleştirildi.

\section{BULGULAR}

Bu çalışmaya Amerikan Diyabet Cemiyeti'nin kılavuzunda (ADA 2015) belirtilen kriterlere göre daha önce teşhisi konulmuş olup takip ve tedavi altında olan, 18 yaş ve üzeri erişkin Tip 2 DM tanısı almış, sistemde $D$ vitamini düzeyleri mevcut 330 hasta alındı.

Çalışmamıza alınan hastaların \%51,2'si kadın (n=169), \%48.8'i erkekti $(n=161)$. Çalışmamıza alınan 330 hastanın yaş ortalaması 53,79 $\pm 10,27$ (min:21, max:84) yıl olarak bulundu. Çalışmamıza katılan hastaların \%54,5'i $(n=180)$ 50-64 yaş arasında bulunmakta idi. Çalışmamıza alınan hastaların \%51,5'i ( $n=170)$ obez, \%34,6'sı ( $n=114)$ fazla kilolu, \%13,9'u ( $n=46)$ normal olarak saptandı. Çalışmamıza alınan hastaların \%8,6'sı $(n=28)$ ilkokulu bitirmemiş, \%54,8'i ( $n=181)$ ilköğretim mezunu, \%13'ü $(n=43)$ lise mezunu, \%23,6'sı $(n=78)$ üniversite ve üzeri mezunuydu. Çalışmamıza alınan hastaların medeni durumları değerlendirildiğinde \%90'ı (n=297) evli, \%10'u ( $n=33$ ) bekar veya boşanmış idi. Çalışmamıza alınan hastaların \%40,9'u ( $n=135)$ ev hanımı, \%18.5'i $(n=61)$ emekli, \%13,6'sı ( $n=45)$ esnaf-serbest meslek, \%9,4'ü (n=58) özel sektörde, \%17,6'sı $(n=31)$ memur olarak çalışmakta idi. Çalışmamıza alınan hastaların \%1,5'i ( $n=5)$ köyde, \%21,8'i ( $n=72)$ ilçede, $\% 76,7$ 'si $(n=253)$ il merkezinde ikamet etmekte idi. 
Tablo 1. Hastaların Sosyo-demografik Özellikleri $(n=330)$

\begin{tabular}{|c|c|c|c|}
\hline Sosyo-demografik Özellikleri & Kategori & $n$ & $\%$ \\
\hline \multirow{2}{*}{ Cinsiyet } & Kadın & 169 & 51,2 \\
\hline & Erkek & 161 & 48,8 \\
\hline \multirow[t]{3}{*}{ Yaş Kategorik } & $20-49$ & 103 & 31,2 \\
\hline & $50-64$ & 180 & 54,5 \\
\hline & 65 ve $\uparrow$ & 47 & 14,3 \\
\hline \multirow[t]{3}{*}{ VKI Kategorik } & Normal & 46 & 13,9 \\
\hline & Fazla Kilolu & 114 & 34,6 \\
\hline & Şişman & 170 & 51,5 \\
\hline \multirow[t]{4}{*}{ Eğitim } & İkokul Bitirmemiş & 28 & 8,6 \\
\hline & İlköğretim & 181 & 54,8 \\
\hline & Lise & 43 & 13,0 \\
\hline & Üniversite ve $\uparrow$ & 78 & 23,6 \\
\hline \multirow[t]{2}{*}{ Medeni Durum } & Evli & 297 & 90,0 \\
\hline & Bekar / Boşanmış & 33 & 10,0 \\
\hline \multirow[t]{5}{*}{ Mesleği } & Ev Hanımı & 135 & 40,9 \\
\hline & Emekli & 61 & 18,5 \\
\hline & Esnaf ve SM & 45 & 13,6 \\
\hline & Memur & 31 & 17,6 \\
\hline & Özel Sektör & 58 & 9,4 \\
\hline \multirow[t]{3}{*}{ Yaşadığı Yer } & Köy & 5 & 1,5 \\
\hline & İlçe & 72 & 21,8 \\
\hline & $\mathrm{il}^{3}$ & 253 & 76,7 \\
\hline \multirow[t]{3}{*}{ Gelir Durumu } & Kötü & 27 & 8,2 \\
\hline & Orta & 244 & 73,9 \\
\hline & İyi & 59 & 17,9 \\
\hline \multirow[t]{3}{*}{ Kardeş Sayısı } & $0-3$ & 91 & 27,6 \\
\hline & $4-6$ & 173 & 52,4 \\
\hline & $7+$ & 66 & 20,0 \\
\hline \multirow[t]{4}{*}{ Sosyal Güvence } & Emekli Sandığı & 107 & 32,4 \\
\hline & SSK & 168 & 50,9 \\
\hline & Bağ-Kur & 55 & 16,7 \\
\hline & Toplam & 330 & 100,0 \\
\hline
\end{tabular}

SM:serbest meslek

Çalışmamıza alınan hastaların \%8,2'sinin $(n=27)$ gelir düzeyi kötü, \%73,9'unun (n=244) gelir düzeyi orta, \%17,9'unun ( $n=59)$ gelir düzeyi iyi idi. Çalışmamıza alınan hastaların \%32,4'ü $(n=107)$ Emekli Sandığı, \%50,9'u ( $n=168)$ SSK, \%16,7'si $(n=55)$ ise BağKur'dan sosyal güvence olarak yararlandığını belirtti (Tablo 1).

Hastalar D vitamini düzeylerine göre gruplara ayrıldığında, vitamin D seviyesi $20 \mathrm{ng} / \mathrm{mL}$ 'nin altında 286 hasta $(\% 86,7), 20 \mathrm{ng} / \mathrm{mL}$ 'nin üzerinde 44 hasta $(\% 13,3)$ saptandı. Bu iki D vitamini grubunun; yaş, cinsiyet, gelir, yaşanılan yer, eğitim durumu, kullanılan DM ilaçları ile ilgili verilere göre dağılımı Tablo 2'de verilmiştir. Yaş grupları, gelir, yaşanılan yer, eğitim durumuna göre gruplar arasında farklılık izlenmedi. Hastaların kullandıkları DM ilaçlarına göre; D vitamini $<20 \mathrm{ng} / \mathrm{mL}$ olan grupta oral antidiyabetik ilaç (OAD) kullanımı istatistiksel olarak anlamlı derecede yüksekti $(p<0,05)$ (Tablo 2).

Hastaların D vitamini ve HbA1c seviyeleri ile diğer kan parametreleri ve $\mathrm{D}$ vitamini ile $\mathrm{HbA} 1 \mathrm{c}$ düzeylerinin birbirleri ile aralarında olan ilişki incelendi. Hastalar D vitamini düzeylerine göre karşılaştıııldığında D vitamini değerleri ile hastaların açlık kan şekeri (AKŞ), tokluk kan şekeri (TKŞ) arasında istatistiksel olarak anlamlı negatif yönde düşük güçte korelasyon $(-r=0,357, \quad p<0,001, \quad-r=0,344, \quad p<0,001$ sırasıyla) bulundu. D vitamini ile trigliserid düzeyi arasında ise istatistiksel olarak anlamlı negatif yönde zayıf korelasyon $(-r=0,131, p<0,05)$ saptandı. D vitamini değerleri ile $\mathrm{HbA} 1 \mathrm{c}$ değerleri arasında negatif yönde düşük güçte korelasyon olduğu tespit edildi ve bu ilişki istatistiksel olarak anlamlı idi $(-r=0,433, p<0,001)$ (Tablo 3).

\section{TARTIŞMA}

Son yıllarda D vitamini ile ilgili yapılan çalışmaların sayısının artmasıyla $D$ vitamininin kemik metabolizması dışında da birçok fonksiyonu olduğu görülmüştür. Bizim elde ettiğimiz sonuçlara 
Tablo 2. Hastaların D vitamini Düzeylerinin Sosyo-demografik ve DM İle İlişkili Özelliklere Göre Karşılaştırılması

\begin{tabular}{|c|c|c|c|c|c|c|c|}
\hline \multirow{3}{*}{ Değişken } & \multirow{3}{*}{ Kategori } & \multicolumn{4}{|c|}{ D Vitamini Düzeyi } & \multirow[b]{3}{*}{$\times 2$} & \multirow[b]{3}{*}{$\mathbf{p}$} \\
\hline & & \multicolumn{2}{|c|}{$<20 \mathrm{ng} / \mathrm{mL}$} & \multicolumn{2}{|c|}{$>20 \mathrm{ng} / \mathrm{mL}$} & & \\
\hline & & $\mathbf{n}$ & $\%$ & $\mathbf{n}$ & $\%$ & & \\
\hline \multirow{2}{*}{ Cinsiyet } & Kadın & 146 & 86,4 & 23 & 13,6 & 0,023 & 0,880 \\
\hline & Erkek & 140 & 87,0 & 21 & 13,0 & & \\
\hline \multirow[t]{3}{*}{ Yaş Grupları } & 20-49 Yaş & 90 & 87,4 & 13 & 12,6 & & \\
\hline & 50-64 Yaş & 154 & 85,6 & 26 & 14,4 & 0,533 & 0,766 \\
\hline & $64+$ Yaş & 42 & 89,4 & 5 & 10,6 & & \\
\hline \multirow[t]{3}{*}{ Gelir } & İyi & 50 & 84,7 & 9 & 15,3 & & \\
\hline & Orta & 210 & 86,1 & 34 & 13,9 & 2,431 & 0,297 \\
\hline & Kötü & 26 & 96,3 & 1 & 3,7 & & \\
\hline \multirow[t]{3}{*}{ Yaşanılan Yer } & ì & 216 & 85,4 & 37 & 14,6 & 1,947 & 0,378 \\
\hline & İlçe & 65 & 90,3 & 7 & 9,7 & & \\
\hline & Köy & 5 & 100,0 & 0 & 0,0 & & \\
\hline \multirow[t]{4}{*}{ Eğitim Durumu } & Illk.Bitirmemiş & 26 & 92,9 & 2 & 7,1 & & \\
\hline & İlköğretim & 156 & 86,2 & 25 & 13,8 & 1,305 & 0,728 \\
\hline & Lise & 36 & 83,7 & 7 & 16,3 & & \\
\hline & Üniversite & 68 & 87,2 & 10 & 12,8 & & \\
\hline \multirow[t]{4}{*}{ DM İlaçları } & $O A D$ & 190 & 83,7 & 37 & 16,3 & 12,363 & 0,006 \\
\hline & İnsülin & 15 & 100,0 & 0 & 0,0 & & \\
\hline & OAD+İnsülin & 71 & 95,9 & 3 & 4,1 & & \\
\hline & İlaç kullanmıyor & 10 & 71,4 & 4 & 28,6 & & \\
\hline
\end{tabular}

göre, D vitamini takviyesinin, eşzamanlı D vitamini eksikliği olan Tip 2 DM hastalarında glisemik kontrol parametrelerinde (AKŞ, TKŞ, HbA1c) iyileşmeye yol açtığını göstermektedir. Bu çalışma aynı zamanda D vitamini eksikliğinin düzeltilmesinin lipit parametreleri (Trigliserid) gibi kardiyovasküler risk faktörlerinde de iyileşmeyi sağladığını kanıtlamaktadır.

Liu et al. (10) yaptıkları bir araştırmada D vitamini düzeylerinin yüksekliğinin tip $2 \mathrm{DM}$ gelişim riskini düşürdüğü bulunmuştur. Yapılan diğer bir çalışmada ise; Targher et al. (11), DM tanılı, 25-hidroksi vitamin D eksikliği olan hastaların $\mathrm{HbA1c}$ düzeylerinin yüksek olduğunu saptamışlardır. Burada D vitamini ile DM arasında olan ilişki; DM'de D vitamininin beta hücre

Tablo 3. Hastaların verilerinin korelasyon analizi

\begin{tabular}{lllll}
\hline & \multicolumn{2}{l}{ D vitamini } & \multicolumn{2}{l}{ HbA1c (\%) } \\
Parametreler & $\mathbf{r}$ & $\mathbf{p}$ & $\mathbf{r}$ & $\mathbf{p}$ \\
\hline Açlık kan şekeri $(\mathrm{mg} / \mathrm{dl})$ & $-0,357$ & $<0,001$ & 0,828 & $<0,001$ \\
Tokluk kan şekeri $(\mathrm{mg} / \mathrm{dl})$ & $-0,344$ & $<0,001$ & 0,777 & $<0,001$ \\
Hemoglobin A1c $(\%)$ & $-0,433$ & $<0,001$ & - & - \\
LDL & $-0,023$ & 0,678 & 0,067 & 0,226 \\
HDL & $-0,015$ & 0,785 & $-0,083$ & 0,133 \\
Total Kolesterol & $-0,035$ & 0,526 & 0,051 & 0,352 \\
Trigliserid & $-0,131$ & 0,017 & 0,207 & $<0,001$ \\
Hgb & $-0,037$ & 0,499 & 0,019 & 0,732 \\
Kreatinin & $-0,031$ & 0,571 & 0,115 & 0,037 \\
GFR & 0,071 & 0,198 & $-0,090$ & 0,104 \\
ALT & 0,043 & 0,434 & 0,088 & 0,109 \\
D vitamini & - & - & $-0,433$ & $<0,001$ \\
\hline
\end{tabular}

fonksiyonunun iyileşmesi üzerine olan etkisi olarak belirtilmiştir. Tekin et al. (12) yaptıkları diğer bir çalışmada yapılmış olan çalışmalarla uyumlu olarak DM tanılı kadın hastalarda $D$ vitamini düzeyinin düştükçe HbA1c değerinin arttığı saptanmıştır. Hyppönen et al. (13) yaptıkları bir çalışmada yaklaşık 30 yıl boyunca tip $1 \mathrm{DM}$ tanılı olan bebeklere 1 yaşına kadar 25-hidroksi vitamin $D$ verilmiş ve ileride bu bebeklerde \%80 oranında tip $1 \mathrm{DM}$ gelişme riskinin düştüğü saptanmıştır. Suzuki et al. (14) çalışmasında toplam 632 Japon hasta ele alınarak tip 2 DM ile D vitaminieksikliği prevalansı arasındaki ilişkiinceleniyor. Bu gözlemsel çalışma sonunda $D$ vitamini düzeyi düşük olanların HbA1c değerlerinin yüksek olduğu fakat D vitamini seviyesi ile DM süresi arasında bir ilişki olmadığı gösterilmiştir. Bizim çalışmamızdakine benzer olarak DM tedavi tercihleri (OAD-insülin) ile $D$ vitamini düzeyleri arasında ilişki saptanmıştır. Bizim çalışmamızda OAD kullananların $D$ vitamini seviyeleri daha düşük saptanırken, bu çalışmada insülin kullananların OAD veya diyet tedavisi alanlara göre $D$ vitamini seviyeleri daha düşük saptanmıştır. Yapılmış olan birçok kesitsel çalışmada, D vitamini ile glisemi ölçümleri arasında ters bir ilişki olduğu bildirilmiştir (15-17). Bazı çalışmalar da ise, D vitamini takviyesi sonrası glikoz kontrol parametrelerinde çelişkili sonuçlar olduğu saptanmıştır $(18,19)$. Fakat bu çalışmalar kısa takipli ve az sayıda hasta ile yapılmış, iyi kontrol edilmemiş araştırmalardır. 
Tip 2 DM'li hastalarda yapılan çalışmaların meta analizlerinden elde edilen sonuçlara göre, tip 2 DM'li hastalara verilen $D$ vitamini desteğinin glisemi ve insülin duyarlılığında küçük yararları olduğunu düşündürmektedir (20-22). Amerika Birleşik Devletleri'nde bulunan sadece iki çalışma tip 2 DM'li hastalarda $D$ vitamini takviyesinin etkisini test etmiştir. Her iki çalışma da kısa süreli ve az sayıda hasta ile yapılmıştır. Soric et al. (23) tip 2 DM olan 37 hasta üzerinde yaptıkları bir çalışmada 12 hafta boyunca 2000 IU/gün vitamin D3 veya 500 mg/gün vitamin $\mathrm{C}$ verilen hastalarda HbA1c'de D vitamini lehine istatistiksel olarak anlamlı bir değişiklik saptanmamıştır. Patel et al. (24) tip 2 DM olan 32 hasta ile yaptıkları çalışmada hastalara 1200 veya $400 \mathrm{lU} /$ gün vitamin D3 verilmiş ve tam verileri bulunan 24 hastada $\mathrm{HbA} 1 \mathrm{c}$ veya insülin direnci kantitatif insülin duyarlılık kontrol indeksinde her iki grup arasında da değişiklik saptanmamıştır.

Pittas et al. (25) yaptıkları çalışmada düşük D vitamini seviyeleri ile tip 2 DM arasında bir ilişki olduğunu bildirmişlerdir. Avustralya DM, Obezite ve Yaşam Tarzı (AusDiab) çalışmasında $25(\mathrm{OH})$ D'deki 25 nmol / L'lik artışın tip 2 DM gelişimi açısından \% 24 daha düşük risk ile ilişkili olduğu bildirilmiştir (OR = 0,76,\% $95 \mathrm{Cl}:$ 0,63, 0,92) (26). Yapılan birçok çalışmada D vitamini eksikliğinin DM gelişimi ile ilişkili olduğu bildirilmiştir $(27,28)$. Bizim çalışmamızda da benzer şekilde $D$ vitamini eksikliği olanlarda AKŞ, TKŞ ve HbA1c değerleri arasında istatistiksel olarak anlamlı negatif korelasyon saptanmıştır.

Gözlemsel çalışmalardaneldeedilenveriler, özellikle uzunlamasına gözlemsel kohort çalışmalarından elde edilen veriler $(29,30), 25(\mathrm{OH}) \mathrm{D}$ konsantrasyonu ve DM arasında ters bir ilişki olduğunu göstermiş ve 25 $(\mathrm{OH}) \mathrm{D}$ konsantrasyonunun DM riski açısından güçlü bir belirteç olduğunu kanıtlamıştır. Benzer sonuç, Çin'de 490 katılımcı ile yapılan kohort çalışmasında da saptanmıştır. Bu prospektif çalışmada, veriler 25 $(\mathrm{OH}) \mathrm{D}$ düzeyi ile prediyabet ve tip $2 \mathrm{DM}$ dahil olmak üzere hipergliseminin başlangıcı arasında bağımsız bir ilişki olduğunu göstermiştir. Ayrıca, $25(\mathrm{OH})$ D eksikliği, sağlıklı Çinli bireylerde insülin direncini artırabilir sonucuna varılmıştır (30).

Sonuç olarak, vit D eksikliği tüm dünyada çok sık görülen bir sağlık sorunudur. Bizim çalışmamızda ve daha önce yapılan çalışmalarda görülen sonuçlar, D vitamini düzeyinin özellikle DM tanılı hastalarda glisemik kontrolle ilgili olabileceğini düşündürmektedir. $\mathrm{Bu}$ nedenle glisemik kontrolü sıkıntılı olan DM'li hastalarda $D$ vitamini düzeylerine bakma gerekliliğinden bahsedilebilir. Ancak D vitamininin glikoz metabolizmasındaki rolünü ve tip 2 DM'nin etyolojisini açıklığa kavuşturmak için daha fazla katılımcıdan oluşan, iyi tasarlanmış, prospektif ve daha uzun takipli daha fazla sayıda çalışma ile bulgularımızın desteklenmesi gerektiğini düşünmekteyiz.

Çıkar Çatışması: Çalışmada herhangi bir çıkar çatışması yoktur.

Finansal Çıkar Çatışması: Çalışmada herhangi bir finansal çıkar çatışması yoktur.

Yazışma Adresi: Duygu İlke Yıldırım, Sağlık Bilimleri Üniversitesi, Konya Eğitim ve Araştırma Hastanesi, Aile Hekimliği Kliniği, Hacı Şaban Mah. Yeni Meram Cad. No:97 Meram,Konya 00042, Türkiye

Telefon: 03322210000 e-posta: azrailla@hotmail.com

\section{KAYNAKLAR}

1. Eroğlu Altinova A, Yetkın İ. Tip 1 Diabetes Mellitus'a yatkınlıkta rolü olabilecek genetik faktörler. MMJ 2011;24(2):126-30.

2. Türk Diyabet Vakfı, Diabet Tanı ve Tedavi Rehberi 2017. http://www.turkdiab.org/i/2013/D\%C4\%B0YABET\%20 REHBER\%C4\%B0\%202013.pdf erişim tarihi: 01.06.2018.

3. Littorin B, Blom P, Scholin A, et al. Lower levels of plasma 25-hydroxyvitamin $D$ among young adults at diagnosis of autoimmune type 1 diabetes compared with control subjects: Results from the nationwide Diabetes Incidence Study in Sweden (DISS). Diabetologia 2006;49:2847-52.

4. Pozzilli P, Manfrini S, Crino A, et al. Low levels of 25-hydroxyvita- min D3 and 1,25-dihydroxyvitamin D3 in patients with newly diagnosed type 1 diabetes. Horm Metab Res 2005;37:680-3.

5. Dong JY, Zhang WG, Chen JJ, et al. Vitamin D intake and risk of type 1 diabetes: A meta-analysis of observational studies. Nutrients 2013;5:3551-62.

6. AfzalS, BojesenSE, NordestgaardBG.Low25-hydroxyvitamin $\mathrm{D}$ and risk of type 2 diabetes: A prospective cohort study and metaanalysis. Clin Chem 2013;59:381-91.

7. Song $Y$, Wang L, Pittas AG, et al. Blood 25-hydroxy vitamin $D$ levels and incident type 2 diabetes: A meta-analysis of prospective studies. Diabetes Care 2013;36(5):1422-8.

8. Holick MF. Vitamin D status: Measurement, interpretation, and clinical application. Ann Epidemiol 2009;19:73-8.

9. Ince B, Yildirim MEC, İsmayilzade M, et al. Vitamin D and systemic effects of vitamin D deficiency. Selcuk Med J 2018;34(2): 84-9.

10. Liu E, Meigs JB, Pittas AG, et al. Predicted 25-hydroxyvitamin D score and incident type 2 diabetes in the Framingham Offspring Study. Am J Clin Nutr 2010;91:1627-33.

11. Targher G, Bertolini L, Padovani R, et al. Serum 25-hydroxyvitamin D3 concentrations and carotid artery intima-media thickness among type 2 diabetic patients. Clin Endocrinol 2006;65:593-7.

12. Tekin $\mathrm{MH}$, Evliyaoğlu $\mathrm{O}$, Yıldırmak $\mathrm{S}$, et al. 25-Hidroksivitamin D3 düzeyleri diyabetin kontrolü ile ilişkili midir? Med Bull Haseki 2016;54:36-40.

13. Hypponen $E$, Laara $E$, Reunanen $A$, et al. Intake of vitamin 
D and risk for type 1 diabetes: A birth- cohort study. Lancet 2:1500-3.

14. Suzuki A, Kotake M, Ono $Y$, et al. Hypovitaminosis $D$ in type 2 diabetes mellitus: Association with microvascular complications and type of treatment. Endocr J 2006;53:50310.

15. Ford ES, Ajani UA, McGuire LC, et al. Concentrations of serum vitamin $D$ and the metabolic syndrome among U.S. adults. Diabetes Care 2005;28:1228-30.

16. Need AG, O'Loughlin PD, Horowitz $M$, et al. Relationship between fasting serum glucose, age, body mass index and serum 25 hydroxyvitamin $D$ in postmenopausal women. Clin Endocrinol 2005;62:738-41.

17. Hypponen E, Power C. Vitamin D status and glucose homeostasis in the 1958 British birth cohort: The role of obesity. Diabetes Care 2006;29:2244-6.

18. Orwoll E, Riddle M, Prince M. Effects of vitamin D on insulin and glucagon secretion in non-insulin-dependent diabetes mellitus. Am J Clin Nutr 1994;59:1083-7.

19. Borissova AM, Tankova T, Kirilov G, et al. The effect of vitamin D3 on insulin secretion and peripheral insulin sensitivity in type 2 diabetic patients. Int J Clin Pract 2003;57:258-61.

20. Wu C, Qiu S, Zhu X, et al. Vitamin D supplementation and glycemic control in type 2 diabetes patients: A systematic review and meta-analysis. Metabolism 2017;73:67-76.

21. Mirhosseini N, Vatanparast $H$, Mazidi $M$, et al. The effect of improved serum 25-hydroxy- vitamin D status on glycemic control in diabetic patients: A meta-analysis. J Clin Endocrinol Metab 2017;102(9):3097-110.

22. Krul-Poel YH, Ter Wee MM, Lips $P$, et al. Management of endocrine disease: The effect of vitamin $D$ supplementation on glycaemic control in patients with type 2 diabetes mellitus: A systematic review and meta-analysis. Eur $\mathrm{J}$ Endocrinol
2017;176(1):R1-4.

23. Soric MM, Renner ET, Smith SR. Effect of daily vitamin D supplementation on $\mathrm{HbA} 1 \mathrm{c}$ in patients with uncontrolled type 2 diabetes mellitus: A pilot study. J Diabetes 2012;4(1):104-5.

24. Patel P, Poretsky L, Liao E. Lack of effect of subtherapeutic vitamin $D$ treatment on glycemic and lipid parameters in Type 2 diabetes: A pilot prospective randomized trial. J Diabetes 2010;2(1):36-40.

25. Pittas A, Lau J, Hu F, et al. Review: The role of vitamin D and calcium in type 2 diabetes. A systematic review and metaanalysis. J Clin Endocrinol Metab 2007;92:2017-29.

26. Gagnon C, Lu ZX, Magliano DJ, et al. Serum 25hydroxyvitamin $\mathrm{D}$, calcium intake, and risk of type 2 diabetes after 5 years: Results from a national, population-based prospective study (the Australian Diabetes, Obesity and Lifestyle study). Diabetes Care 2011;34:1133-8.

27. Kositsawat J, Freeman VL, Gerber BS, et al. Association of A1C levels with vitamin D status in U.S. adults: Data from the National Health and Nutrition Examination Survey. Diabetes Care 2010;33:1236-8.

28. Sollid ST, Hutchinson MY, Fuskevåg OM, et al. No effect of high-dose vitamin D supplementation on glycemic status or cardiovascular risk factors in subjects with prediabetes. Diabetes Care 2014;37:2123-31.

29. Ye Z, Sharp SJ, Burgess S, et al. Association between circulating 25-hydroxyvitamin $\mathrm{D}$ and incident type 2 diabetes: A Mendelian randomisation study. The Lancet Diabetes \& Endocrinology 2015;3(1):35-42.

30. Gao Y, Zheng T, Ran X. Vitamin D and incidence of prediabetes or type 2 diabetes: A four-year follow-up community-based study. Dis Markers 2018;1926308 